\title{
Exteroceptive cues in taste-aversion learning, no artifact: Reply to Holder
}

\author{
PER-OLOW SJÖDÉN \\ Uppsala University, Uppsala, Sweden \\ and \\ TREVOR ARCHER \\ Astra Läkemedel AB, Södertälje, Sweden
}

\begin{abstract}
Holder (1988) has raised several objections to our work on the role of exteroceptive contextual stimuli in taste-aversion learning by rats. Our main conclusion from that work is that tonguetactile stimuli from the drinking spout constitute the likely basis for findings of contextual bottle control over learned taste aversions. Holder suggests that our results are confounded by taste cues from the fluid containers. We refute this suggestion by presenting data from two experiments showing contextual bottle control, even though potential taste cues from the drinking bottles were eliminated. We also point to the fact that some of Holder's criticisms are based on misreadings of our various reports.
\end{abstract}

In a series of publications from our laboratory during the last 9 years, we have documented findings from a project concerned with the role of contextual stimuli in taste-aversion learning in rats (Archer \& Sjödén, 1979a, 1979b, 1980, 1981, 1982, 1985; Archer, Sjödén, \& Carter, 1979; Archer, Sjödén, \& Nilsson, 1984, 1985; Archer, Sjödén, Nilsson, \& Carter, 1979, 1980; Sjödén \& Archer, 1981, 1983). Our general conclusion, summarized in a recent review paper (Archer et al., 1985), is that "a contextual compound stimulus consisting of bottles, compartments and an odor element was demonstrated to exert strong control over postconditioning saccharin intake" and that "the relative salience of the contextual elements was demonstrated to be in the order of bottles $>$ compartments $>$ odor, and tongue-tactile bottle stimuli are likely to be the most salient"' (p. 262).

\section{Holder's Criticism}

In a comment that specifically addresses four of our studies (Archer et al., 1980; Archer, Sjödén, \& Carter, 1979; Archer, Sjödén, Nilsson, \& Carter, 1979; Sjödén \& Archer, 1983), Holder (1988) has raised several objections to our conclusions that were based upon perceived problems with our experimental methodology. Since Holder's criticism is, if uncontested, potentially serious for the status of most of our research, we find it essential to deal with it at some length.

Among the four studies discussed by Holder, there is one to which he seems to take particular exception (Sjö-

The present research was supported by Grants 584/79, 897/80, 422/81, and 424/82 from the Swedish Council for Research in the Humanities and Social Sciences, and by grants from Astra Chemicals. Reprints may be obtained from Per-Olow Sjödén, Department of Clinical Psychology, Uppsala University, Box 1225, S-751 42 Uppsala, Sweden. dén \& Archer, 1983). In that study, we reported six experiments that investigated the roles of taste and bottle stimuli in taste-aversion learning in rats. Specifically, we found that a taste (saccharin) stimulus was more salient than stimuli from the drinking bottle when paired singly with illness (lithium chloride). When a novel compound stimulus consisting of saccharin and bottle was paired with illness, the bottle element acquired greater aversive strength than did the taste. Finally, in an overshadowing-potentiation paradigm, we found that the taste stimulus potentiated conditioning to the bottle stimulus. Thus, animals that had experienced the taste + bottle compound paired with illness evidenced a stronger aversion to the bottle than did animals for whom the bottle alone had been paired with illness. The latter finding parallels results from other studies on potentiation in animal learning (Clarke, Westbrook, \& Irwin, 1979; Durlach \& Rescorla, 1980; Galef \& Osborne, 1978; Rusiniak, Hankins, Garcia, \& Brett, 1979).

The starting point of Holder's argument is that our results are surprising for at least four reasons. The first concerns our demonstration of potentiation. Holder cites several studies showing potentiation to be a replicable phenomenon. Thus, we seem to agree that potentiation of a weaker by a stronger stimulus occurs under certain (so far relatively unexplored) circumstances in which overshadowing was previously the only outcome to be expected.

The second point referred to by Holder is that "most investigators in animal learning recognize that not all stimuli are equally well associated with all important events" (p. 231). Here, he seems to imply that we have advocated an equipotentiality notion with respect to stimulus associability. This is, however, untrue and must be based on a misreading of our reports. As is clearly evi- 
dent from several of our publications (e.g., Archer et al., 1985; Sjödén \& Archer, 1983), we do not maintain that bottle stimuli (or other exteroceptive cues) are as well associated with illness as are taste stimuli. In single-cue procedures, taste is more salient than bottle stimuli, but in compound procedures, it seems that the bottle stimulus acquires the greater associative strength, possibly through potentiation. Our proposal is that exteroceptive stimuli arising from the animal's surroundings, including nongustatory stimuli from the fluid source, are attended to by rats in illness-based aversive conditioning. However, we are strongly opposed to a dichotomous standpoint according to which taste and odor stimuli are associable with illness whereas other stimuli are not.

Holder's third point refers to the fact that our results are not immediately compatible with the neural-based model of aversive conditioning proposed by Garcia and his co-workers (Garcia, Lasiter, Bermudez-Rattoni, \& Deems, 1985). His fourth point is that the effects of contextual stimuli in taste-aversion learning has often been very small, whereas we have found strong effects of bottle cues with delays of up to $30 \mathrm{~min}$ and after only one or two trials. What we have found is that when one type of bottle is used for saccharin presentations during conditioning and a different type is used during extinction, the aversion is much weaker. Furthermore, when a saccharin aversion is extinguished with a type of bottle different from that used during conditioning, the aversion to saccharin taken from the conditioning bottle largely remains. A problem of interpretation arises because our two types of bottles differ in several dimensions. Thus, it may be unclear as to exactly what dimensions are used by the animals in making the discriminations. The most obvious difference between the bottle types is that in one, a plastic bottle, the drinking spout is fitted with two stainless steel balls ("noisy bottle"), whereas in the other, a glass bottle ("silent bottle"), it is not. The balls provide tactile stimulation of the tongue as well as a distinctive clicking noise when licked. At an early stage of our project, we performed a study to clarify the role of the lick-produced noise (Archer, Sjödén, \& Carter, 1979). Our conclusion was that the "auditory cues do not seem to contribute to the observed effects"' (p. 224). Thus, we have nowhere proposed that our results demonstrate a noise-illness association, inasmuch as our own data contradict such a proposal. Instead, we have furthered the notion that "tongue-tactile stimuli remain as the likely basis for the contextual bottle control over learned taste aversions" (Archer et al., 1985, p. 238). Whether this notion is equally problematical to the cue-to-consequence tradition, and the neurally based model of learning developed within it (Garcia et al., 1985), we leave for Holder to decide.

\section{No Artifact}

At the heart of Holder's criticism is the suggestion that our methodology harbors a serious artifact. Since our "noisy" bottles were always made of plastic and the "silent" ones were made of glass, Holder suggests that the taste of saccharin may have been different when taken from plastic as opposed to glass containers. Thus, a taste difference, rather than a difference in tactile stimulation of the tongue, may have formed the basis for the rats' discriminative behavior. On the basis of previous literature, we find this proposal unlikely. On the basis of empirical data to be presented below, we suggest that it can be ruled out.

There is considerable evidence that tactual or somatosensory stimuli associated with the animal's drinking response are of importance in aversion learning. In a study by Nachman, Rauschenberger, and Ashe (1977), it was found that the size of the spouts of the fluid containers was an important stimulus dimension. Similarly, Nachman (1970) showed that rats are capable of learning an aversion to the temperature of water. Revusky and Parker (1976) have demonstrated marked aversions to unflavored water presented in a particular drinking cup. Holder states that the effect of stimuli other than taste (thus, contextual stimuli) on illness associations has been very small, and cites a few studies to support this. We suggest a careful reading of the three articles cited above. Against the empirical background formed by these studies, we find it reasonable to maintain that the most likely basis for bottle-specific saccharin aversions resides in tongue-tactile stimuli.

The most effective argument against Holder's proposal of an artifact should, of course, be based on empirical data. Such a demonstration should show that rats can form an aversion to saccharin that is specific to the drinking spout used, irrespective of the material of which the fluid container is made. Experiment 1 investigates this possibility.

\section{EXPERIMENT 1}

\section{Method}

Animals. Thirty-two male Sprague-Dawley rats (AB Anticimex, Sollentuna, Sweden) with a mean body weight of $350 \mathrm{~g}$ (range 330 to $380 \mathrm{~g}$ ) were assigned randomly to four groups matched for body weight. They were kept on a 12-h-on:12-h-off lighting schedule (lights on at $0700 \mathrm{~h}$ ) in a room thermostatically maintained at $22^{\circ} \pm 1^{\circ} \mathrm{C}$. Housing consisted of individual Perspex cages $(16.5 \times 22.5 \times 13.5 \mathrm{~cm})$ with metal grid covers that had space for food and water bottles. Food (Lab Chow R 3, Astra-Ewos, Södertälje, Sweden) was available ad lib throughout the experiment. During a 2-week acclimatization period following the rats' arrival at the laboratory, water was freely available in standard glass bottles with metal nozzles that had a 2-mm-wide drinking hole.

Apparatus. All phases of the experiment were performed with the animals in their home cages. Saccharin $(.2 \% \mathrm{w} / \mathrm{v}$ sodium saccharin solution) was used as the drinking fluid. Two types of fluid containers were used: one made of glass and one made of plastic (Ehret, West Germany). Both types could be fitted with "noisy" or "silent" spouts. The "noisy" spouts had a 6-mm-wide opening at the tip and contained two stainless steel balls with a diameter of $6.3 \mathrm{~mm}$. These were placed, one on top of the other, in the spout. The balls moved up and down and caused a distinctive clicking noise during licking. The "silent" spouts were the same as those used during acclimatization. 
Procedure. Following acclimatization, all animals were accustomed to a 30-min/day drinking schedule $(0815-0845 \mathrm{~h})$ by gradually reducing the drinking period from $24 \mathrm{~h}$ to $\mathrm{l} \mathrm{h}$ and to 30 min during a 6-day period. All subsequent fluid presentations except preference tests took place between these hours. After the 6-day training period, saccharin replaced water and all groups were given two conditioning trials with the saccharin drinking period being followed, after approximately $15 \mathrm{~min}$, by a .15 $\mathrm{M}$ lithium chloride $(\mathrm{LiCl})$ injection in a dose of $10 \mathrm{ml} / \mathrm{kg}$. On the conditioning trials, Groups GS and GD drank from glass bottles, and Groups PS and PD drank from plastic bottles. All bottles were fitted with "noisy" spouts. One day of 30 min of water drinking from glass bottles with "silent" spouts was inserted between the conditioning days.

During extinction, Groups GS and PS (S = same) continued their saccharin intake from the same spouts as during conditioning, whereas the "noisy" spouts were replaced by "silent" spouts for Groups GD and PD (D = different). Five extinction trials were employed. During the preference tests, all animals were given two bottles, one with saccharin and one with water, for $8 \mathrm{~h}$, starting at $0815 \mathrm{~h}$. Groups GS and GD were given glass bottles, and Groups PS and PD, plastic bottles. All bottles were fitted with "noisy" spouts. One day of water drinking was inserted between the preference tests. The percent preference for saccharin in relation to total fluid intake was computed.

Throughout, fluid intake was recorded by weighing the bottles before and after drinking. Values were recorded to the nearest $1.0 \mathrm{~g}$.

\section{Results and Discussion}

The results are presented in Figure 1. In accordance with our previous studies, split-plot analyses of variance were run separately for the conditioning and extinction phases. Nonparametric statistics were used for the preference test data. During conditioning, there was a significant effect of groups $[F(3,28)=5.5, p<.01]$, but the Tukey HSD test indicated no pairwise between-group differences. Independent $t$ tests showed that Group GS drank significantly less saccharin on both conditioning trials than did Groups PS and PD. However, there were no differences between the $S$ and $D$ groups drinking from glass or from plastic bottles.
The extinction data indicate that the presence ( $\mathrm{S}$ groups) or absence (D groups) of the drinking spout employed during conditioning heavily influenced saccharin intake. In addition to significant effects of groups and trials, there was a groups $\times$ trials interaction $[F(12,112)=6.6$, $p<.01]$. HSD tests revealed significant GS $<$ GD differences on Extinction Trials 2-5 and significant PS < PD differences on Trials 3-5. Thus, the change of drinking spout affected saccharin intake from glass as well as from plastic bottles.

The analysis of preference test data was complicated by several strongly skewed distributions, and the median values did not agree well with the means (medians: Test 1 : $\mathrm{GS}=30.5, \mathrm{GD}=4.5, \mathrm{PS}=72.5, \mathrm{PD}=5.0$; Test 2: $\mathrm{GS}=24.5, \mathrm{GD}=4.0, \mathrm{PS}=64.5, \mathrm{PD}=3.5$ ). We therefore decided to use the Mann-Whitney $U$ test, which showed $U$ s between 12 and 15 for all within-trial GS $>$ DS and PS $>$ PD comparisons $(p<.05)$. This indicates that the animals experiencing, during extinction, a drinking spout that was different from that used in conditioning retained their aversion to a higher degree than did those that had the conditioning spout during extinction as well. Again, we are forced to conclude that the drinking source stimuli are highly salient when illness is the aversive agent.

These data illustrate that rats develop saccharin aversions that are specific to the characteristics of the drinking spout from which they take saccharin during conditioning. In addition, they demonstrate that extinction of a saccharin aversion is specific to the type of spout employed at extinction, and that the aversion to saccharin taken from the conditioning spout is largely spared under these circumstances. Thus, we feel we can safely reject Holder's (1988) suggestion that the results of our previous studies are due to an artifact of our equipment.

In our previous research, we have demonstrated that contextual stimuli are sufficiently salient in taste-aversion learning to support second-order conditioning as well as sensory preconditioning (Archer, Cotic, \& Järbe, 1986;

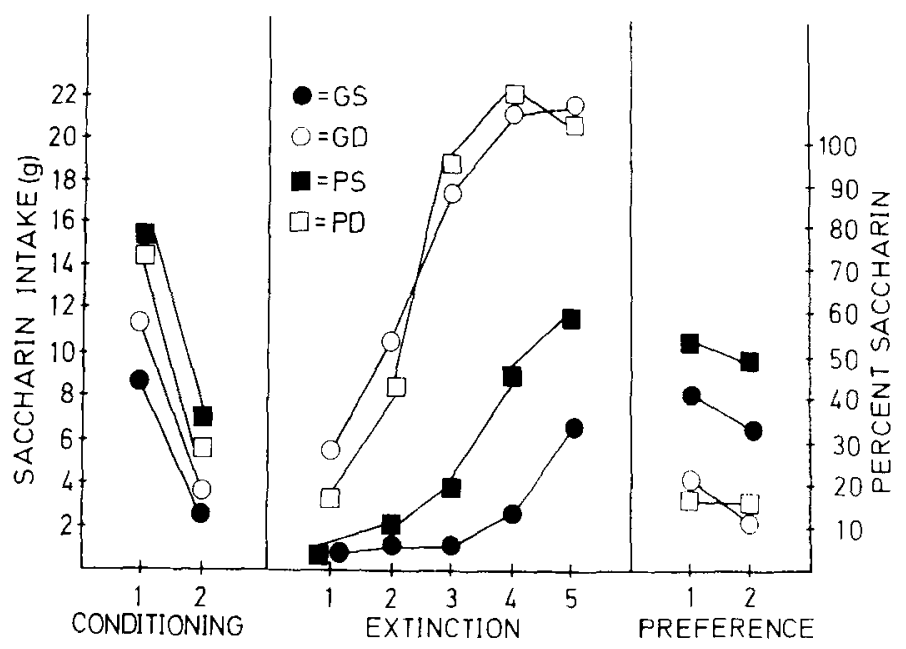

Figure 1. Mean values of saccharin intake (conditioning and extinction) and saccharin preference (preference tests) of four groups of rats in Experiment 1. 
Archer \& Sjödén, 1982). Instead of replicating these studies with the "plastic taste"' controlled for, we decided to explore whether or not another well-documented phenomenon could be shown for contextual bottle stimuli. It has been repeatedly shown that the preconditioning presentation of a potential CS retards subsequent conditioning and facilitates extinction of that CS (Mackintosh, 1974). This phenomenon has been termed latent inhibition, and it has been shown after taste preexposure in tasteaversion learning (Nachman, 1970; Revusky \& Bedarf, 1967; Wittlin \& Brookshire, 1968). Our aim was to show that preexposure to a specific drinking spout retards the establishment of an aversion to saccharin drunk from that type of spout, although "plastic taste" is controlled for. In an earlier study, we demonstrated context-specific latent inhibition in a taste-aversion paradigm (Archer, Mohammed, \& Järbe, 1983), although Holder's artifact criticism may be leveled at that study.

\section{EXPERIMENT 2}

\section{Method}

The general method of Experiment 1 was maintained with the following exceptions. Thirty-six male Sprague-Dawley rats, with a mean body weight of $350 \mathrm{~g}$ (range 330 to $380 \mathrm{~g}$ ), were assigned randomly to four groups matched for body weight. Before conditioning, four daily trials of preexposure to saccharin for $30 \mathrm{~min} /$ day were given to all animals in their home cages. Group GP (P = preexposure) was offered saccharin in glass bottles fitted with "noisy"' spouts, Group GN (N = no preexposure) was given glass bottles with "silent" spouts, Group PP was given plastic bottles with "noisy" spouts, and Group PN was given plastic bottles with "silent" spouts. Two conditioning trials were then administered on which all groups drank saccharin from "noisy" spouts, G groups from glass bottles and P groups from plastic bottles. All groups were given three postconditioning test trials with the same saccharin/bottle/spout arrangement as during conditioning. One day of 30 min of water drinking from glass bottles with "silent" spouts was inserted between each of the preconditioning, conditioning, and test trials, with the exception of Preconditioning Trials 3-4 and of Conditioning Trial 2-Test 1 , when 2 days were used.

\section{Results and Discussion}

There were no significant differences between the groups during the preexposure phase or on the first conditioning trial (prior to $\mathrm{LiCl}$ injections). Saccharin intake from the second conditioning trial and the three test trials is illustrated in Figure 2. If spout characteristics are as salient as we expected, the preexposure to these cues should serve to reduce aversion strength for Groups GP and PP in comparison to that for Groups GN and PN. $U$ tests revealed GP $>$ GN differences of saccharin intake on the second conditioning trial and on the first two test trials ( $U$ s between 4 and 18), and PP $>$ PN differences on the first two test trials ( $U_{\mathrm{s}} 11$ and 21 ). There were no differences on the third test trial. Thus, overall, the results verified our prediction based on inhibitory learning to the spout characteristics. Again, there is no possibility that the animals used plastic taste cues.

Although Holder's contention that rats, using taste, can discriminate water in plastic tubes from water in glass bot-

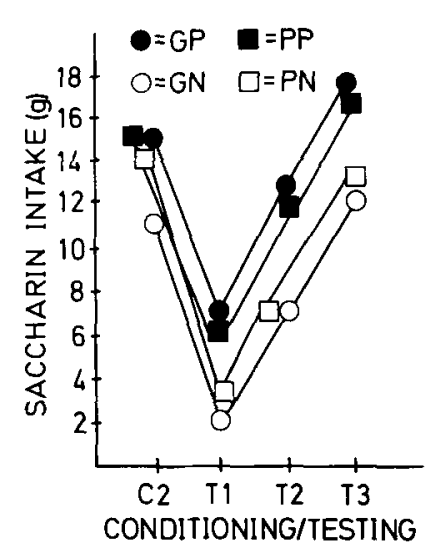

Figure 2. Mean saccharin intake on the second conditioning trial and on three test trials by four groups of rats in Experiment 2.

tles is not at all unreasonable, it is quite mistaken here. Thus, we consider that contention as a most unlikely explanation for the strong effects we have found in many studies. In the first place, in most of our experiments, the rats have had to discriminate not between water, but between saccharin solutions in different bottles. The saccharin taste may mask any "plastic" taste. Secondly, the conclusion by Garcia, McGowan, and Green (1972) that "the rats could discriminate the water in plastic bottles ... on the basis of taste" (p. 6) is based on highly suspect empirical data. In fact, the report states that the procedure used was "informal tests by Robert A. Koelling, conducted by hand in the animal room" (p. 6). Rats may not be overly impressed by the relative formality of our test procedures, but a less reliable methodology than that used by Garcia et al. is hard to conceive. Holder also cites two unpublished experiments by Finch (1985), in which it was purportedly shown that plastic bottles can operate as a taste stimulus. This is a further illustration that the issue that Holder raises rests on a very shaky empirical foundation. Furthermore, to judge from Holder's description, the design of Finch's (1985) experiments is confusing in relation to the issue that he raises. Third, it is interesting to note that Garcia et al.'s interpretation of the original observation was that the discrimination between plastic tubes and glass bottles was based on taste stimulation. If, as stated, drinking spouts were used with the plastic test tubes and drinking tubes were attached to the glass bottles, a viable competing interpretation would be that the discrimination was based on spout characteristics. Finally, we now have data (unpublished) from experiments in which aversions to "noisy" spouts were produced even though all animals drank water from plastic bottles.

In conclusion, we maintain the position that tonguetactile stimulation from drinking is sufficiently salient to serve as the basis for spout-specific taste-aversion learning in rats. The data from Experiment 2 extend our previous findings by showing reliable inhibitory learning to drinking spout characteristics. As the present data show, spout characteristics are salient enough to produce effects of a strength equal to that obtained in our previous studies, 
in spite of the fact that, in the present study, the animals could not use taste cues from the fluid containers. Thus, to use Holder's own expression, we have reported results similar to those found previously in our project, but now without any possibility of a confound by a "plastic" taste.

\section{REFERENCES}

ArCher, T., Cotic, T., \& J̈̈rke, T. U. C. (1986). Noradrenaline and sensory preconditioning in the rat. Behavioral Neuroscience, 100 , 704-711.

ARCher, T., Mohammed, A. K., \& JärBe, T. U. C. (1983). Latent inhibition following systemic DSP4: Effects due to presence and absence of contextual cues in taste-aversion learning. Behavioral \& $\mathrm{Neu}$ ral Biology, 38, 287-306.

ARCHER, T., \& SJÖDÉN, P.-O. (1979a). Neophobia in taste-aversion conditioning: Individual differences and effects of contextual changes. Physiological Psychology, 7, 364-369.

ARCHER, T., SJödÉN, P.-O. (1979b). Positive correlation between pre- and postconditioning saccharin intake in taste-aversion learning. Animal Learning \& Behavior, 7, 144-148.

ARCHER, T., \& SJöDÉN, P.-O. (1980). Context-dependent taste-aversion learning with a familiar conditioning context. Physiological Psychology, 8, 40-46.

ARCHER, T., SJöDÉN, P.-O. (1981). Environment-dependent tasteaversion extinction: A question of stimulus novelty at conditioning Physiological Psychology, 9, 102-108.

ARCHER, T., \& SJÖDÉN, P.-O. (1982). Higher-order conditioning and sensory preconditioning of a taste aversion with an exteroceptive CSI. Quarterly Journal of Experimental Psychology, 34B, 1-17.

ARCHER, T., \& SJöDÉN, P.-O. (1985). Effects of CS concentration in taste-aversion learning: Problems in assessing aversion strength. Scandinavian Joumal of Psychology, 26, 42-52.

ArCher, T., SJödén, P.-O., CARTer, N. (1979). Control of tasteaversion extinction by exteroceptive cues. Behavioral \& Neural Biology, 25, 217-226.

ARCHER, T., SJödÉN, P.-O., \& Nilsson, L. G. (1984). The importance of contextual elements in taste-aversion learning. Scandinavian Joumal of Psychology, 25, 251-257.

ARCher, T., SuöDÉN, P.-O., \& Nilsson, L. G. (1985). Contextual control of taste-aversion conditioning and extinction. In P. D. Balsam \& A. Tomie (Eds.), Context and learning (pp. 225-271). Hillsdale, NJ: Erlbaum.

Archer, T., Sjödén, P.-O., Nilsson, L. G., \& Carter, N. (1979). Role of exteroceptive background context in taste-aversion conditioning and extinction. Animal Learning \& Behavior, 7, 17-22.

Archer, T., SJödén, P.-O., Nilsson, L. G., \& Carter, N. (1980). Exteroceptive context in taste-aversion conditioning and extinction: Odour, cage and bottle stimuli. Quarterly Journal of Experimental Psychology, 32, 197-214.

Clarke, J. C., Westbrook, R. F., \& Irwin, J. (1979). Potentiation instead of overshadowing in the pigeon. Behavioral \& Neural Biology, 25, 18-29.

Durlach, P. J., \& Rescorla, R. A. (1980). Potentiation rather than overshadowing in flavor-aversion learning. An analysis in terms of within-compound associations. Journal of Experimental Psychology: Animal Behavior Processes, 6, 175-187.

FiNCH, B. (1985). Effects of excitatory contexts on conditioned inhibition in taste aversion. Unpublished doctoral dissertation proposal, University of California, Los Angeles.

GaLeF, B. G., \& Osborne, B. (1978). Novel taste facilitation of the association of visual cues with toxicosis in rats. Journal of Comparative \& Physiological Psychology, 92, 907-916.

Garcia, J., Lasiter, P. S., Bermudez-Rattoni, F., \& Deems, D. A. (1985). A general theory of aversion learning. In N. S. Brennan \& P. Bronstein (Eds.), Experimental assessments and clinical applications of conditioned food aversions (pp. 8-21). New York: New York Academy of Sciences.

Garcia, J., McGowan, B. K., \& GreEn, K. F. (1972). Biological constraints on conditioning. In A. H. Black \& W. F. Prokasy (Eds.), Classical conditioning: II. Current research and theory (pp. 3-27). New York: Appleton-Century-Crofts.

Holder, M. D. (1988). Possible role of confounded taste stimuli in conditioned taste aversions. Animal Leaming \& Behavior, 16, 231-234.

Mackintosh, N. J. (1974). The psychology of animal learning. London: Academic Press.

NACHMAN, M. (1970). Learned taste and temperature aversions due to lithium chloride sickness after temporal delays. Journal of Comparative \& Physiological Psychology, 73, 31-37.

Nachman, M., Rauschenberger, J., Ashe, J. H. (1977). Studies of learned aversions using nongustatory stimuli. In L. M. Barker, M. R. Best, \& M. Domjan (Eds.), Leaming mechanisms in food selection (pp. 395-417). Waco, TX: Baylor University Press.

Revusky, S. H., \& BeDarf, E. W. (1967). Association of illness with prior ingestion of novel foods. Science, 155, 219-220.

RevUsKy, S., \& PARKer, L. A. (1976). Aversions to unflavored water and cup drinking produced by delayed sickness. Journal of Experimental Psychology: Animal Behavior Processes, 2, 343-353.

Rusiniak, K. W., Hankins, W. G., Garcia, J., \& Brett, L. (1979). Flavor-illness aversions: I. Potentiation of odor by taste in rats. Behavioral \& Neural Biology, 25, 1-17.

SJÖDÉN, P.-O., \& ARCHER, T. (1981). Associative and nonassociative effects of exteroceptive context in taste-aversion conditioning with rats. Behavioral \& Neural Biology, 33, 74-92.

Suödén, P.-O., \& ARCHER, T. (1983). Potentiation of a bottle aversion by taste in compound conditioning with rats. Experimental Animal Behaviour, 2, 1-18.

WitTlin, W. A., \& Brookshire, K. H. (1968). Apomorphine-induced conditioned aversion to a novel food. Psychonomic Science, 12, 217-218

(Manuscript received August 20, 1985; revision accepted for publication March 5, 1987.) 